\title{
Is the elimination of cervical cancer now 3 times easier? One-dose vaccine efficacy has far-reaching implications
}

\author{
Paweł Koczkodaj', Joakim Dillner², Marta Mańczuk \\ 'Maria Sklodowska-Curie National Research Institute of Oncology, Warsaw, Poland \\ ${ }^{2}$ Karolinska Institute, Stockholm, Sweden
}

More and more studies have proven that low trust in vaccines has become a universal phenomenon, regardless of the region of the world and type of vaccine [1-3]. Particularly intense public debate on vaccines efficacy and safety has been (and still is) visible during the COVID-19 pandemic. A plethora of misconceptions, myths and fake news on vaccines has come to the fore recently, causing a lack of trust, not only in COVID-19 vaccines. Searching for new paths to cope with this public health challenge should be one of the key points of current international and national health policy agendas. In this context, recent research results look very promising, i.e. a single dose of vaccination against HPV has a similar efficacy to two and three doses [4]. These results may have far-reaching implications - primarily in a public health context, as it may enable a much faster eradication of HPV regionally and worldwide, moreover, those reluctant to get the HPV vaccine will be more likely to take just one dose, rather than three.

Europe's Beating Cancer Plan launched by the European Commission at the beginning of 2021 assumes vaccinations of target population of girls will be at the level of $90 \%$ by 2030 as well as acceleration of vaccinations among boys. However, the document describes a "fully vaccinated"target population, implying having completed a 3-dose scheme which can be much more difficult taking into consideration high social HPV vaccine hesitancy. Moreover, in the coming years (at least 4-5 years), due to rapidly growing demand, there are predictions of further HPV-vaccine shortages on the world market. Fur- thermore, despite the plans of new manufacturers to enter the market, it will take some time to begin efficient production (even 4 years are needed for manufacturing the final product). Moreover, legal difficulties impede shifting HPV vaccinations supplies from one country to another [5]. Discussing all of these obstacles, it is crucial to significantly increase social trust in HPV vaccinations. Implementation of the one-dose vaccination scheme seems to be one of the easiest and most beneficial ways to achieve this goal. Additionally, faster HPV eradication can be obtained by combining vaccination and screening in organised programs $[6,7]$ and this strategy would be greatly facilitated if both screening and vaccination could be completed in a single visit.

The WHO has specifically called for further research on innovative ways to achieve the elimination goal faster. The fact that it has also now been shown for the quadrivalent vaccine (that a single-dose HPV vaccination is as effective as a 3-doses full scheme), means the results could help to overcome one of the most important barriers to broad vaccine coverage - low social trust.

Conflict of interest: none declared

\section{Paweł Koczkodaj}

Maria Sklodowska-Curie National Research Institute of Oncology

Cancer Epidemiology and Primary Prevention Department

ul. Roentgena 5

02-781 Warszawa, Poland

e-mail: pawel.koczkodaj@pib-nio.pl

\footnotetext{
How to cite:

Koczkodaj P, Dillner J, Mańczuk M. Is the elimination of cervical cancer now 3 times easier? One-dose vaccine efficacy has far-reaching implications. NOWOTWORY J Oncol 2022; 72: 65-66.

This article is available in open access under Creative Common Attribution-Non-Commercial-No Derivatives 4.0 International (CC BY-NC-ND 4.0) license, allowing to download articles and share them with others as long as they credit the authors and the publisher, but without permission to change them in any way or use them commercially.
} 
Received: 16 Nov 2021

Accepted: 21 Nov 2021

\section{References}

1. Kunitoki K, Funato M, Mitsunami M, et al. Access to HPV vaccination in Japan: Increasing social trust to regain vaccine confidence. Vaccine. 2021; 39(41): 6104-6110, doi: 10.1016/j.vaccine.2021.08.085, indexed in Pubmed: 34507858

2. Karafillakis $E$, Simas $C$, Jarrett $C$, et al. HPV vaccination in a context of public mistrust and uncertainty: a systematic literature review of determinants of HPV vaccine hesitancy in Europe. Hum Vaccin Immunother. 2019; 15(7-8): 1615-1627, doi: 10.1080/21645515.2018.1564436, indexed in Pubmed: 30633623.

3. Troiano G, Nardi A. Vaccine hesitancy in the era of COVID-19. Public Health. 2021; 194: 245-251, doi: 10.1016/j.puhe.2021.02.025, indexed in Pubmed: 33965796.
4. Basu P, Malvi S, Joshi S, et al. Vaccine efficacy against persistent human papillomavirus (HPV) 16/18 infection at 10 years after one, two, and three doses of quadrivalent HPV vaccine in girls in India: a multicentre, prospective, cohort study. The Lancet Oncology. 2021; 22(11): 1518-1529, doi: 10.1016/s1470-2045(21)00453-8.

5. Garland SM, Stanley MA, Giuliano AR, et al. IPVS Policy Committee. IPVS statement on "Temporary HPV vaccine shortage: Implications globally to achieve equity". Papillomavirus Res. 2020; 9: 100195, doi: 10.1016/j. pvr.2020.100195, indexed in Pubmed: 32205196.

6. Bosch FX, Robles C, Díaz M, et al. HPV-FASTER: broadening the scope for prevention of HPV-related cancer. Nat Rev Clin Oncol. 2016; 13(2): 119132, doi: 10.1038/nrclinonc.2015.146, indexed in Pubmed: 26323382.

7. Dillner J, Elfström KM, Baussano I. Prospects for accelerated elimination of cervical cancer. Prev Med. 2021; 153: 106827, doi: 10.1016/j. ypmed.2021.106827, indexed in Pubmed: 34599922 